\title{
Case Report: Ectopic third molar in the maxillary sinus with \\ infected dentigerous cyst assessed by cone beam CT [version
}

\section{1; peer review: 2 approved]}

\author{
Khairy Elmorsy1, Lubna K. Elsayed (D)2, Sara M. El Khateeb (iD)2,3 \\ ${ }^{1}$ Oral and Maxillofacial Surgery Department, Cairo University, Cairo, Egypt \\ ${ }^{2}$ Basic Dental Sciences Department, College of Dentistry, Princess Nourah bint Abdulrahman University, Riyadh, Saudi Arabia \\ ${ }^{3}$ Oral Medicine, Periodontology, Diagnosis and Oral Radiology Department, Faculty of Dentistry, Ain Shams University, Cairo, Egypt
}

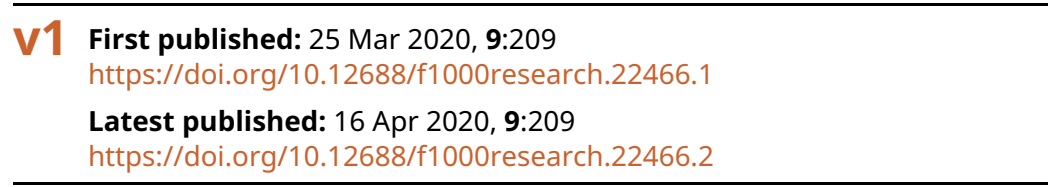

\section{Abstract}

Ectopic development of teeth in nondental areas is uncommon, especially in the maxillary sinus. A panoramic radiograph is the routine diagnostic radiographic examination performed for this type of eruption, although cone beam computed tomography (CBCT) is highly recommended for further localization of the ectopic tooth and assessment of the characteristics of any associated lesion before a surgical procedure. We report a case of a 13-year-old female student who presented with purulent discharge posterior to the upper right second molar with a bad taste and foul odour. Radiographic examination revealed a maxillary third molar tooth located at the posterosuperior aspect of the right maxillary sinus with a hyperdense lesion surrounding the crown, obliterating the sinus cavity. Both the tooth and dentigerous cyst were surgically removed under general anaesthesia through Caldwell-Luc antrostomy. After a three-month follow-up, the patient was symptom free and had an uneventful recovery. The rare and critical location of the reported third molar along with the infected dentigerous cyst indicates its complete enucleation to avoid complications as recurrence or malignant transformation.

\section{Keywords}

Ectopic, tooth Eruption, Maxillary Sinus, Molar, Cone Beam CT

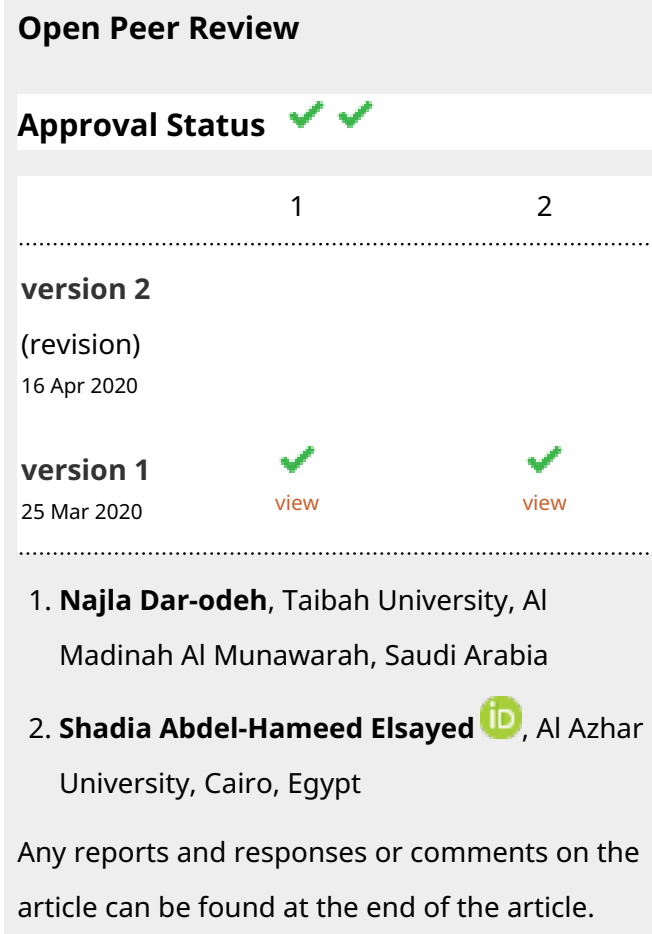

1 2

version 2

(revision)

16 Apr 2020

version 1

25 Mar 2020

1. Najla Dar-odeh, Taibah University, Al Madinah Al Munawarah, Saudi Arabia

2. Shadia Abdel-Hameed Elsayed (D), Al Azhar University, Cairo, Egypt

Any reports and responses or comments on the article can be found at the end of the article. 
Corresponding author: Sara M. El Khateeb (saraelkhateeb77@gmail.com)

Author roles: Elmorsy K: Investigation, Methodology, Writing - Review \& Editing; Elsayed LK: Data Curation, Formal Analysis,

Investigation, Methodology, Resources, Validation, Writing - Original Draft Preparation, Writing - Review \& Editing; El Khateeb SM:

Formal Analysis, Investigation, Methodology, Resources, Validation, Visualization, Writing - Original Draft Preparation, Writing - Review

\& Editing

Competing interests: No competing interests were disclosed.

Grant information: This research was funded by the Deanship of Scientific Research at Princess Nourah bint Abdulrahman University through the Fast-track Research Funding Program.

Copyright: (c) 2020 Elmorsy $\mathrm{K}$ et al. This is an open access article distributed under the terms of the Creative Commons Attribution License, which permits unrestricted use, distribution, and reproduction in any medium, provided the original work is properly cited.

How to cite this article: Elmorsy K, Elsayed LK and El Khateeb SM. Case Report: Ectopic third molar in the maxillary sinus with infected dentigerous cyst assessed by cone beam CT [version 1; peer review: 2 approved] F1000Research 2020, 9:209 https://doi.org/10.12688/f1000research.22466.1

First published: 25 Mar 2020, 9:209 https://doi.org/10.12688/f1000research.22466.1 


\section{Introduction}

An ectopic eruption is a condition characterized by the presence of a tooth in a non-dentate area, distant from its usual anatomical location. The aetiology of an ectopic eruption can be unclear; however, several theories have been put forward to describe the rise of this condition, such as: developmental disturbances like cleft palate; pathological processes like large cysts, which displace tooth buds to other areas; odontogenic and rhinogenic infections; or iatrogenic activity ${ }^{1-4}$.

The maxillary sinus is an unusual location for an ectopic eruption, although some cases have been reported with unconventional management approaches ${ }^{5-7}$.

Ectopic eruption reporting is rare; this case reports the unusual location of the eruption as well as the radiographic assessment and the surgical approach and is a contribution to the literature on this topic.

\section{Case report}

Initial presentation

A 13-year-old Caucasian female student reported to the oral and maxillofacial surgery clinic with the chief complaint of purulent discharge oozing just distal to the upper right second molar, with a bad taste and foul odour, that started two weeks before seeking treatment. Upon clinical examination, the patient had no intraoral or extraoral swelling, and there was a full complement of teeth on that arch except for teeth \#18 and \#28. All teeth were firm, vital and non-carious. A panoramic radiograph revealed ectopic eruption of the right maxillary third molar in the maxillary sinus with hyperdense lesion surrounding its crown and obliterating the sinus cavity (Figure 1).

\section{Diagnostic assessment and intervention}

Further radiographic investigation using cone beam computed tomography (CBCT) determined the exact location of the maxillary molar and the lesion extension since the molar was seen in close proximity to the infraorbital rim. CBCT showed the ectopic third molar with incompletely formed roots located in the posterosuperior aspect of the right maxillary sinus with a close approximation to the orbital floor superiorly and pterygoid plates posteriorly (Figure 2a). The third molar was surrounded by a well-defined corticated hyperdense lesion measuring $23 \times 36 \times 35 \mathrm{~mm}$, occupying almost the whole cavity of the right maxillary sinus and causing mediolateral expansion of the alveolar ridge. The CBCT also revealed the destructive effect of the associated pericoronal lesion on the right maxillary sinus floor and buccal cortical plate, distal to tooth \#17,

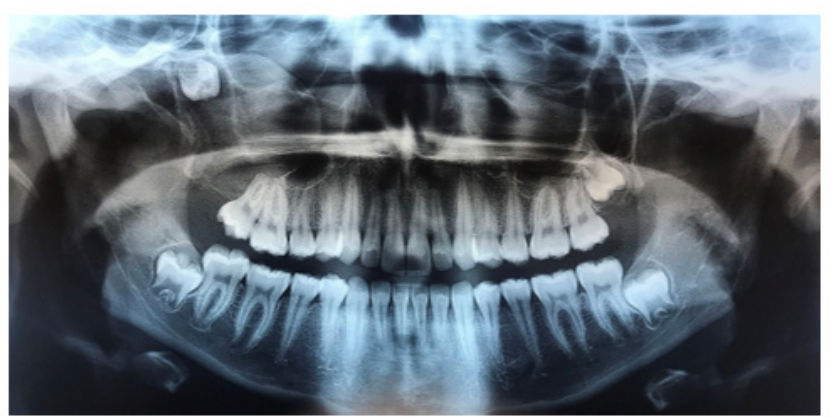

Figure 1. Preoperative panoramic radiograph showing an ectopic eruption of the right maxillary third molar in a superior position near pterygomaxillary fissure inside the right maxillary sinus and surrounded by well-defined hyperdense lesion obliterating the right maxillary sinus cavity.

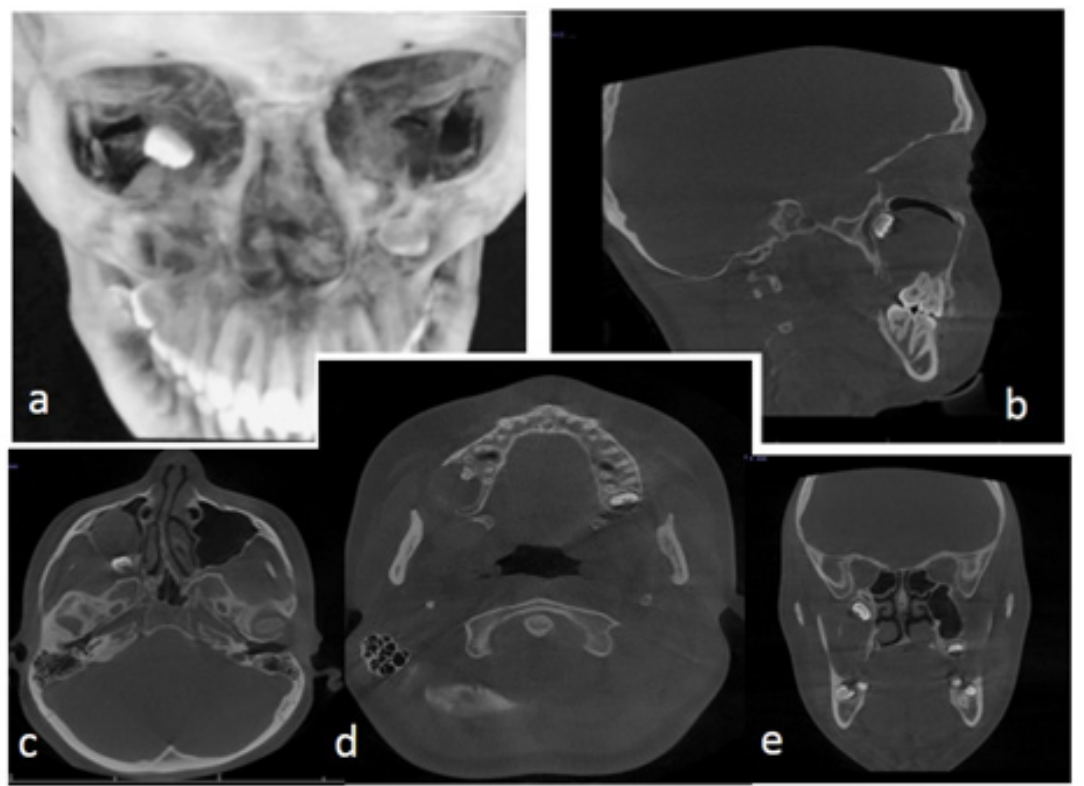

Figure 2. Multiplanar cone beam computed tomography (CBCT) sections: (a) three-dimensional; (b) sagittal; (c, d) axial; (e) coronal slices showing the posterosuperior position of the ectopic right third maxillary molar inside the maxillary sinus with associated pericoronal hyperdense lesion and radiographic evidence of oroantral communication due to its destructive effect on the maxillary sinus floor and the alveolar ridge. 
causing oroantral communication, which explains the reason for the purulent discharge, the chief complaint of the patient (Figure 2b, 2c, 2d and 2e). Differential diagnosis of the detected lesion was dentigerous cyst, odontogenic keratocyst or Gorlin cyst. Based on the clinical and radiographical examination, the surgical removal of the ectopic third molar along with cyst enucleation was planned through an intraoral approach under general anaesthesia induced via nasopharyngeal intubation. Induction of anaesthesia was achieved with propofol $2 \mathrm{mg} / \mathrm{kg}$, fentanyl $1 \mu \mathrm{gm}$ and atracurium $0.5 \mathrm{mg} / \mathrm{kg}$, then maintained with propofol infusion $200 \mu \mathrm{gm} / \mathrm{kg} / \mathrm{min}$, fentanyl $1 \mu \mathrm{gm} / \mathrm{kg} /$ hour and atracurium $0.1 \mathrm{mg} / \mathrm{kg}$ every 20 minutes.

An oral and maxillofacial surgeon with 15 years of experience performed lateral sinus antrostomy, utilizing a standard Caldwell-Luc approach, with a bony window created in the anterolateral wall of the maxillary sinus (Figure 3a). An incision was made through the Schneiderian membrane to enter the maxillary sinus. The cystic lining was identified, and the pus was drained prior to the complete removal of the cystic lining and extraction of the ectopic maxillary third molar (Figure 3b). The antrum was thoroughly irrigated, and the cystic lining was placed in a $10 \%$ buffered formalin solution for subsequent histopathological examination and final diagnosis. The flap was closed with chromic catgut sutures with good approximation of edges. Postoperative antibiotics were given to the patient in form of $500 \mathrm{mg}$ of amoxicillin every eight hours for a minimum of five days with an analgesic (325mg acetaminophen every four hours per day), also one dose of betamethasone $4 \mathrm{mg}$ was given to prevent postoperative edema of the cheek, and the patient was instructed not to blow her nose for two weeks.

Histopathologic examination reported a cystic cavity lined by a thin non-keratinized stratified squamous epithelium. Part of the epithelial lining showed hyperplasia due to inflammation and long-standing lesion, and a connective tissue wall infiltrated with chronic inflammatory cells and composed of fibroblasts, collagen fibres and blood vessels, suggesting an infected dentigerous cyst (Figure 4).
Follow-up

A panoramic radiograph and CBCT were performed three months after the surgery. CBCT axial cuts revealed some bone formation in the mediolateral dimension when compared to the preoperative radiographs, which indicates that the bone is in the healing process (Figure 5a).

Healing appeared to be better clinically than radiographically, the bone requiring longer to time form and be detected radiographically. There is improved bone healing in younger patients, and so we expect a quick healing process with our patient.

Postoperative CBCT scans showed opacification and mucosal lining thickening of the right maxillary sinus, as well as continued discontinuity of the posterolateral floor and part of the anterior wall of the right maxillary sinus (Figure $5 \mathrm{~b}$ and $5 \mathrm{c}$ ).

\section{Discussion}

Ectopic eruption of teeth into dentate regions is relatively common, but such a condition in non-dentate areas like the mandibular condyle, sigmoid notch, or nasal cavity is rare, and the exact aetiology of this phenomenon is not clear ${ }^{8}$.

Occasionally, the tooth may erupt into the maxillary sinus and could be asymptomatic ${ }^{9}$ or cause symptoms such as sinusitis or swelling, facial pain, rhinorrhoea, nasal obstruction and headache $^{10}$. In the present case, the patient presented with purulent discharge distal to upper second molar and panoramic radiograph showed an ectopic third molar associated with a pericoronal lesion.

Some studies report that panoramic radiography is the radiographic examination of choice in ectopic cases because of its accuracy in detecting these structures and the low level of radiation to which the patient is subjected ${ }^{6-11}$. However, the major disadvantage of two-dimensional panoramic radiography is the difficulty in interpreting the exact location of the ectopic tooth and the associated pathology because of the superimposition of different bony structures ${ }^{12}$.
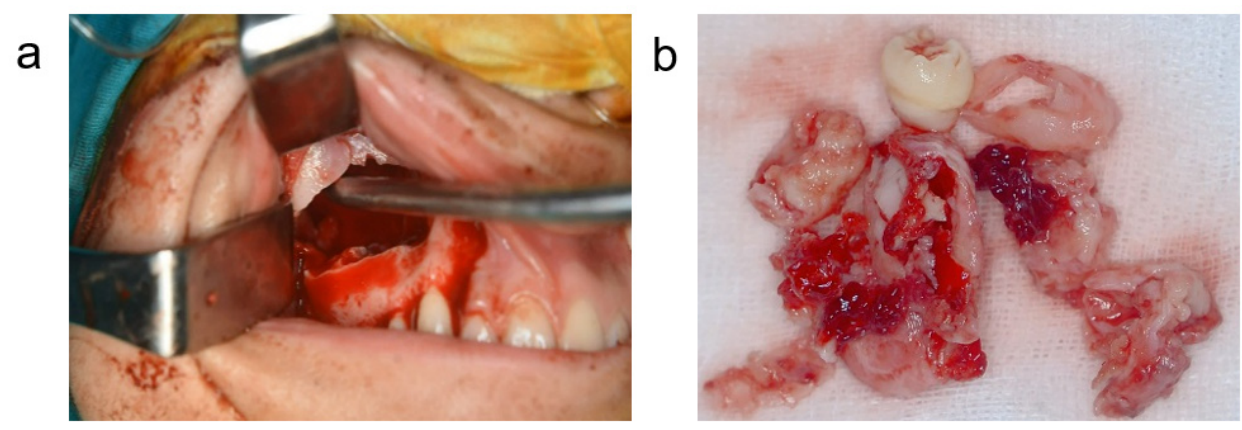

Figure 3. (a) Perioperative image showing the bony window created in the anterior wall of the sinus. (b) Underdeveloped ectopic molar with cystic lining. 
a

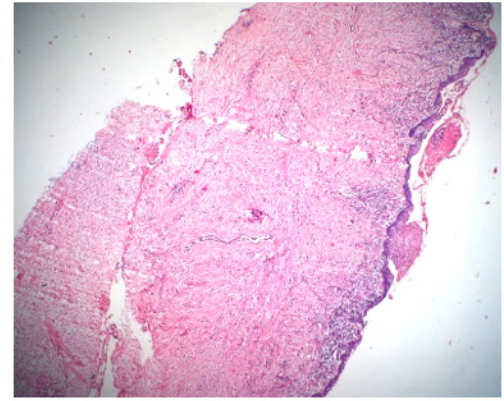

$\mathrm{b}$

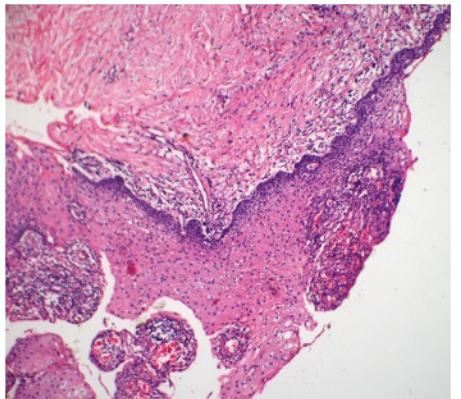

C

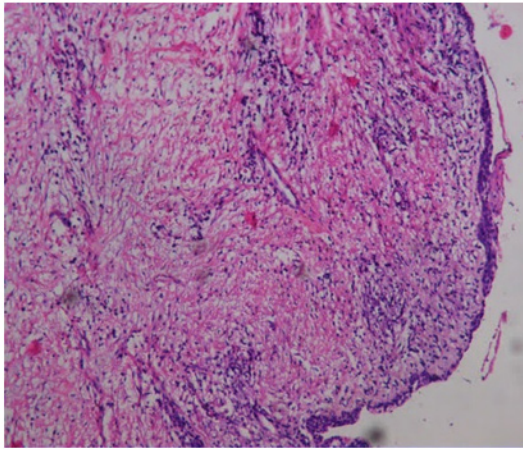

Figure 4. (a, b) Photomicrograph of infected dentigerous cyst $(\times 4, \times 10)$. (c) Photomicrograph of infected dentigerous cyst showing thin non-keratinized epithelium $(\times 4)$.

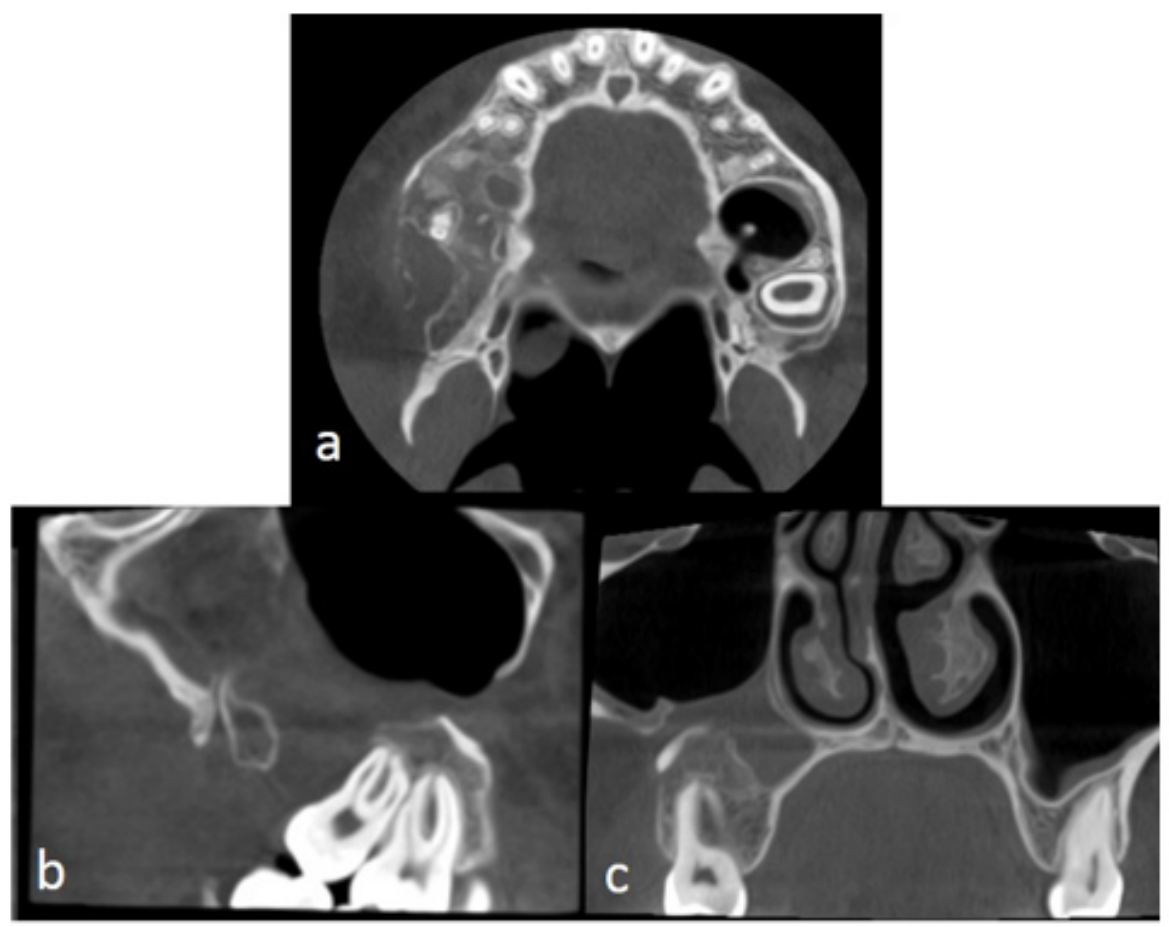

Figure 5. Multiplanar cone beam computed tomography (CBCT) slices: (a) axial cut showing bone formation medially; (b, c) sagittal and coronal cuts showing discontinuity of the antral floor and part of the anterior antral wall with oroantral communication starting distal to tooth \#16. 
CBCT presents an accurate three-dimensional imaging modality that offers highly diagnostic images with a sub-millimetre resolution, short scanning time and reduced radiation dose up to 15 times less than multi-slice CT scans ${ }^{13}$.

The CBCT assessment of our case allowed us to precisely locate the ectopic molar and showed the exact extension and effect of the associated pericoronal lesion on the surrounding structures. This allowed the preoperative identification of the cause of the purulent discharge and aided the surgeon during the surgical procedure, mainly to avoid any surgical complications due to the proximity to the orbital floor and pterygoid plates.

Alqerban et al. and Botticelli et al. reported better accuracy and significant interobserver agreement in the evaluation of ectopic canine location when using CBCT compared to panoramic radiography ${ }^{11,14}$. The smallest field of view matched the clinical indication, recommended to minimize the radiation exposure to the patient ${ }^{15}$.

In our case, histopathologic examination showed an associated infected dentigerous cyst with the ectopic molar, similar to what has been described previously in the literature, where the dentigerous cysts are the most common pathologic lesion associated with ectopic eruptions ${ }^{16}$.

Caldwell-Luc antrostomy and full enucleation of the cyst was performed on our patient, as it provides a direct view of the maxillary sinus and allows instrumentation, irrigation and removal of large objects, making it the treatment of choice for surgery at the maxillary sinus ${ }^{17}$.

Various techniques for managing ectopic teeth are mentioned in the literature, such as endoscopic assisted procedures ${ }^{18,19}$, as well as extra and trans-oral approaches ${ }^{20}$. Endoscopic approaches have less morbidity post and intraoperatively ${ }^{21}$. Liau et al. utilized the endoscopically assisted CaldwellLuc approach for safer instrumentation of the supero-lateral aspect of the maxillary sinus, allowing direct line access for visualization of potential orbital floor defects. He concluded that this approach allowed accurate visualization of inaccessible areas of the maxillary sinus with the ability to perform surgical intervention under direct line access as required ${ }^{19}$.

In the present paper, we report a case of infected dentigerous cyst associated with an ectopic molar within the maxillary sinus. Surgical removal for both was performed, and the entire pathologic antral tissue was removed completely and assessed histologically. There were no post-surgical complications, and the patient's postoperative healing was satisfactory.

\section{Conclusion}

Ectopic tooth eruptions in the maxillary sinus are rare. However, its association with dentigerous cysts is relatively common. A standard Caldwell-Luc approach is the management of choice to surgically extract the ectopic tooth along with excision of the pathologic tissue to avoid sinus or ophthalmic complications. Asymptomatic cases should be managed with a similar protocol due to their tendency to form cysts or malignancies.

\section{Data availability}

All data underlying the results are available as part of the article and no additional source data are required.

\section{Consent}

Written informed consent for publication of their clinical details and clinical images was obtained from the parent of the patient.
1. Bodner L, Tovi F, Bar-Ziv J: Teeth in the maxillary sinus--imaging and management. J Laryngol Otol. 1997; 111(9): 820-824. PubMed Abstract | Publisher Full Text

2. O'meara WF: Ectopic Eruption Pattern in Selected Permanent Teeth. J Dent Res. 1962; 41(3): 607-616.

Publisher Full Text

3. Lee FP: Endoscopic extraction of an intranasal tooth: A review of $\mathbf{1 3}$ cases. Laryngoscope. 2001; 111(6): 1027-1031. PubMed Abstract | Publisher Full Text

4. Baykul T, Doğru H, Yasan H, et al.: Clinical impact of ectopic teeth in the maxillary sinus. Auris Nasus Larynx. 2006; 33(3): 277-281. PubMed Abstract | Publisher Full Text

5. Goh $\mathrm{YH}$ : Ectopic eruption of maxillary molar tooth--an unusual cause of recurrent sinusitis. Singapore Med J. 2001; 42(2): 080-081. PubMed Abstract

6. Chagas Júnior OL, Moura LB, Sonego CL, et al:: Unusual Case of Sinusitis Related to Ectopic Teeth in the Maxillary Sinus Roof/Orbital Floor: A Report. Craniomaxillofacial Trauma Reconstr. 2016; 09(03): 260-263. PubMed Abstract | Publisher Full Text | Free Full Text

7. Bello SA, Oketade IO, Osunde OD: Ectopic 3rd Molar Tooth in the Maxillary Antrum. Case Rep Dent. 2014; 2014: 620741.

PubMed Abstract | Publisher Full Text | Free Full Text
8. Findik Y, Baykul T: Ectopic third molar in the mandibular sigmoid notch: Report of a case and literature review. J Clin Exp Dent. 2015; 7(1): e133-e137. PubMed Abstract | Publisher Full Text | Free Full Text

9. Kheir MK, Sheikhi M: Ectopic third molar in maxillary sinus: an asymptomatic accidental finding. Egypt J Otolaryngol. 2019; 35(2): 219-221. Reference Source

10. Lamb JF, Husein OF, Spiess AC: Ectopic molar in the maxillary sinus precipitating a mucocele: a case report and literature review. Ear Nose Throat $J$. 2009; 88(8): E6-E11.

PubMed Abstract

11. Botticelli S, Verna C, Cattaneo PM, et al:: Two- versus three-dimensional imaging in subjects with unerupted maxillary canines. Eur J Orthod. 2011; 33(4): 344-349. PubMed Abstract | Publisher Full Text

12. Loubele M, Maes F, Schutyser F, et al:: Assessment of bone segmentation quality of cone-beam CT versus multislice spiral CT: a pilot study. Oral Surg Oral Med Oral Pathol Oral Radiol Endod. 2006; 102(2): 225-234. PubMed Abstract | Publisher Full Text

13. Scarfe WC, Farman AG, Sukovic P: Clinical Applications of Cone-Beam Computed Tomography in Dental Practice. J Can Dent Assoc. 2006; 72(1): 75-80. PubMed Abstract

14. Alqerban $\mathrm{A}$, Jacobs $\mathrm{R}$, Fieuws $\mathrm{S}$, et al: Comparison of two cone beam computed 
tomographic systems versus panoramic imaging for localization of impacted maxillary canines and detection of root resorption. Eur J Orthod. 2011; 33(1): 93-102.

PubMed Abstract | Publisher Full Text

15. Serrant PS, McIntyre GT, Thomson DJ: Localization of ectopic maxillary canines -- is CBCT more accurate than conventional horizontal or vertical parallax? J Orthod. 2014; 41(1): 13-18.

PubMed Abstract | Publisher Full Text

16. Buyukkurt MC, Omezli MM, Miloglu O: Dentigerous cyst associated with an ectopic tooth in the maxillary sinus: a report of 3 cases and review of the literature. Oral Surg Oral Med Oral Pathol Oral Radiol Endod. 2010; 109(1): 67-71. PubMed Abstract | Publisher Full Text

17. Sivolella S, Ricci S, Busca M, et al:: Maxillary dentigerous cyst associated with an ectopic third molar in the maxillary sinus: a literature review and report of six consecutive cases. Oral Surg. 2014; 7(S1): 72-78.

Publisher Full Text
18.

Christmas DA, Mirante JP, Yanagisawa E: Endoscopic view of a maxillary dentigerous cyst. Ear Nose Throat J. 2008; 87(6): 316 PubMed Abstract | Publisher Full Text

19. Liau I, Lynch N, Hearn B, et al.: Endoscopically Assisted Modified Caldwell-Luc Approach to Enucleation of Dentigerous Cyst With Ectopic Tooth From the Maxillary Sinus. J Craniofac Surg. 2018; 29(6): e568-e570. PubMed Abstract | Publisher Full Text

20. Rai A, Rai NJ, Rai MA, et al:: Transoral removal of ectopic maxillary third molar situated superiorly to maxillary antrum and posteroinferiorly to the floor of orbit. Indian J Dent Res. 2013; 24(6): 756-758.

PubMed Abstract | Publisher Full Text

21. Gangadhara Somayaji K, Rajeshwary A, Ramlan S, et al.: Ectopic premolar tooth in the maxillary sinus: A case report and review of literature. Arch Med Health Sci. 2013; 1(1): 48-51.

Publisher Full Text 


\section{Open Peer Review}

\section{Current Peer Review Status:}

\section{Version 1}

Reviewer Report 03 April 2020

https://doi.org/10.5256/f1000research.24794.r61700

(C) 2020 Elsayed S. This is an open access peer review report distributed under the terms of the Creative Commons Attribution License, which permits unrestricted use, distribution, and reproduction in any medium, provided the original work is properly cited.

\section{Shadia Abdel-Hameed Elsayed}

Faculty of Dental Medicine for Girls, Al Azhar University, Cairo, Egypt

Thanks for this interesting, fully described, detailed, well written case.The manuscript needs minor revisions.

Some points need to be declared.

\section{Title}

Title need to be summarized and "assessed by cone beam CT" could be removed from the title. CT nowadays used routinely to diagnose the midface lesions for its difficult interpretation on plan panoramic films.

Case reports are usually describing a very rare condition however dentigerous cyst in the maxillary sinus is not uncommon.

Figure $\mathbf{3}$ is an intraoperative photo not perioperative image.

Usually dentigerous cyst is diagnosed mainly by association with impacted tooth so the conclusion of the paper needs to be more accurate as this case is not ectopic eruption.

The following paragraph is more accurately describing the present case: In the present paper, we report a case of infected dentigerous cyst associated with an ectopic molar within the maxillary sinus. Surgical removal for both was performed, and the entire pathologic antral tissue was removed completely and assessed histologically. There were no post-surgical complications, and the patient's postoperative healing was satisfactory.

\section{Introduction}

Ectopic eruption definition needs more justification as the present tooth is ectopic but associated with large maxillary cyst and pushed superiorly as result of cyst enlargement.

Authors did not report any prevalence rate of the dentigerous cyst (which usually associated with impacted wisdom) in the maxillary sinus and also the rate for ectopic impacted teeth in the sinus.

\section{Operation}

The cystic lesion had discharge and was diagnosed as infected cyst, does the surgeon treat 
infection before opening the sinus especially as the cyst was communicate with the oral cavity and possibility of recurrent fistula is high? (Preoperative management of infected sinus is not mentioned).

Why is nasal anticongestant not prescribed as routine post sinus surgery (note that the sinus membrane appears still edematous in the $\mathrm{CBCT}$ )?

Is the background of the case's history and progression described in sufficient detail? Yes

Are enough details provided of any physical examination and diagnostic tests, treatment given and outcomes?

Yes

Is sufficient discussion included of the importance of the findings and their relevance to future understanding of disease processes, diagnosis or treatment?

Yes

Is the case presented with sufficient detail to be useful for other practitioners?

Yes

Competing Interests: No competing interests were disclosed.

Reviewer Expertise: Oral and Maxillofacial Surgery

I confirm that I have read this submission and believe that I have an appropriate level of expertise to confirm that it is of an acceptable scientific standard.

Author Response 04 Apr 2020

sara elkhateeb, Princess Nourah University, Riyadh, Saudi Arabia

\section{Comment No 1}

Title need to be summarized and "assessed by cone beam CT" could be removed from the title.

Reply to No 1

We prefer to keep the title as it is, we think its more enriching to the title to elaborate on the radiographic assessment of the case, especially that we noticed some ectopic cases were not evaluated using CBCT.

\section{Comment No 2}

Case reports are usually describing a very rare condition however dentigerous cyst in the maxillary sinus is not uncommon.

\section{Reply to No 2}

Our report is focusing on the ectopic location of the molar "which is a rare condition" and being associated with dentigerous cyst. 


\section{Comment No 3}

Figure 3 is an intraoperative photo not perioperative image.

\section{Reply to No 3}

The prefix "Peri" means "Intra or during", so no change will be performed. FYI prefix "Pre" means "before"

\section{Comment No 4}

Usually dentigerous cyst is diagnosed mainly by association with impacted tooth so the conclusion of the paper needs to be more accurate as this case is not ectopic eruption. The following paragraph is more accurately describing the present case: In the present paper, we report a case of infected dentigerous cyst associated with an ectopic molar within the maxillary sinus. Surgical removal for both was performed, and the entire pathologic antral tissue was removed completely and assessed histologically. There were no postsurgical complications, and the patient's postoperative healing was satisfactory.

\section{Reply to No 4}

a) The term "eruption" means emission, ejection or discharge. Since the molar was clinically "visible" in the maxillary sinus, it is scientifically correct to describe it as "eruption" inside maxillary sinus. Also, the term "ectopic eruption" was previously reported in papers published in indexed journals in same ectopic cases in maxillary sinus.

\section{Paper examples:}

Sharma S, Chauhan JS. Bilateral ectopic third molars in maxillary sinus associated with dentigerous cyst: A rare case report. International journal of surgery case reports. 2019 Jan 1; 61:298-301.

Lombroni LG, Farronato G, Santamaria G, Lombroni DM, Gatti P, Capelli M. Ectopic teeth in the maxillary sinus: A case report and literature review. Indian Journal of Dental Research. 2018 Sep 1;29(5):667.

Jalal H, Hicham S, Lahcen K, Karim EK. Dentigerous Cyst Associated with an Ectopic Third Molar in the Maxillary Sinus: Report of Cases and Review of Literature. Oral \& Maxillofacial Pathology Journal. 2018 Jan 1;9(1).

b) Conclusion preferably to contain a recommendation, your kind suggestion of the paragraph is already included in the paper, so we prefer to keep both.

\section{Comment No 5}

Ectopic eruption definition needs more justification as the present tooth is ectopic but associated with large maxillary cyst and pushed superiorly as result of cyst enlargement

\section{Reply to No 5}

We already put general statement in the introduction about the definition of ectopic eruption and the different theories of the causes of its occurrence were discussed in the discussion part. In our case the third molar is in ectopic location and erupted inside the maxillary sinus where the associated pericoronal cyst was the suggested theory for its location.

\section{Comment No 6}

Authors did not report any prevalence rate of the dentigerous cyst (which usually associated with impacted wisdom) in the maxillary sinus and also the rate for ectopic impacted teeth in the sinus. 


\section{Reply to No 6}

As it is a case report without review of literature, we didn't go through prevalence of reported conditions, but we agree it is advantageous to be included.

\section{Comment No 7}

The cystic lesion had discharge and was diagnosed as infected cyst, does the surgeon treat infection before opening the sinus.

\section{Reply to No 7}

It was a chronic condition due to long standing infection, managing the case in this case will be symptomatic only, so we thought that best managing will be through surgical eradication of the source.

\section{Possibility of recurrent fistula is high?}

Patient had a 12 months post-surgery follow-up and no fistula was developed.

Why is nasal anticongestant not prescribed as routine post sinus surgery?

\section{Reply}

It was prescribed.

Competing Interests: No competing interest

Reviewer Report 02 April 2020

\section{https://doi.org/10.5256/f1000research.24794.r61698}

(C) 2020 Dar-odeh $\mathbf{N}$. This is an open access peer review report distributed under the terms of the Creative Commons Attribution License, which permits unrestricted use, distribution, and reproduction in any medium, provided the original work is properly cited.

\section{Najla Dar-odeh}

Department of Oral Basic and Clinical Sciences, College of Dentistry, Taibah University, Al Madinah Al Munawarah, Saudi Arabia

This study describes a case of a purulent infection that originated in a dentigerous cyst associated with an ectopic third molar in the maxillary sinus. Three diagnostic methods were utilized in this study. A panoramic radiograph was employed initially, followed by a more accurate imaging technique of CBCT to get more detailed information on the extent of the lesion, and to elicit a more accurate differential diagnosis. Finally a histopathological examination was done to achieve a final diagnosis. Successful treatment outcomes were accompanied by a satisfactory follow-up period, and this further increased the chances for a good prognosis.

The term "ectopic eruption" was used throughout the text, however, taking into consideration the age of the patient and the definition of "eruption", it is preferable to replace it with the term "ectopic tooth". 
Literature review was thorough, however, several references were published more than a decade ago. It would be much improved by inclusion of more recent literature, especially case reports that tackle the topic of ectopic third molar in the maxillary sinus, and that take in consideration the young age of the patient.

1. Discussion: first paragraph mentions that exact aetiology is not clear, what do you think the aetiology for ectopic tooth is in your case?

2. Discussion: How many cases of ectopic teeth in the maxillary sinus were reported so far? And how many of them were for third molars?

I thank authors for the informative manuscript and the solid treatment plan. I also encourage them to write a literature review on this topic.

Is the background of the case's history and progression described in sufficient detail? Yes

Are enough details provided of any physical examination and diagnostic tests, treatment given and outcomes?

Yes

Is sufficient discussion included of the importance of the findings and their relevance to future understanding of disease processes, diagnosis or treatment?

Yes

Is the case presented with sufficient detail to be useful for other practitioners?

Yes

Competing Interests: No competing interests were disclosed.

Reviewer Expertise: Oral Medicine.

I confirm that I have read this submission and believe that I have an appropriate level of expertise to confirm that it is of an acceptable scientific standard.

Author Response 04 Apr 2020

sara elkhateeb, Princess Nourah University, Riyadh, Saudi Arabia

\section{Comment No 1}

The term "ectopic eruption" was used throughout the text, however, taking into consideration the age of the patient and the definition of "eruption", it is preferable to replace it with the term "ectopic tooth".

Reply to No 1:

The term "eruption" means emission, ejection or discharge. Since the molar was clinically "visible" in the maxillary sinus, it is scientifically correct to describe it as "eruption" inside maxillary sinus. 
Also, the term "ectopic eruption" was previously reported in papers published in indexed journals in similar ectopic cases in maxillary sinus.

\section{Paper examples:}

-Sharma S, Chauhan JS. Bilateral ectopic third molars in maxillary sinus associated with dentigerous cyst.

-A rare case report. International journal of surgery case reports. 2019 Jan 1; 61:298-301.

-Lombroni LG, Farronato G, Santamaria G, Lombroni DM, Gatti P, Capelli M. Ectopic teeth in the maxillary

sinus: A case report and literature review. Indian Journal of Dental Research. 2018 Sep 1;29(5):667.

-Jalal H, Hicham S, Lahcen K, Karim EK. Dentigerous Cyst Associated with an Ectopic Third Molar in the Maxillary Sinus: Report of Cases and Review of Literature. Oral \& Maxillofacial Pathology Journal. 2018 Jan 1;9(1).

\section{Comment No 2}

Literature review was thorough, however, several references were published more than a decade ago.

\section{Reply to No 2:}

We agree to some extent with this comment, reference no. 2 will be replaced with:

Lombroni L, Farronato G, Santamaria G, Lombroni D, Gatti P, Capelli M. Ectopic teeth in the maxillary sinus: A case report and literature review. Indian J Dent Res. 2018;29(5):667.

For the rest of references, we cannot make any changes in them as we think that having diversity in time ranges in the references and enriches our literature, as we included also 2013/14/18 and 19 articles.

\section{Comment No 3}

Discussion: first paragraph mentions that exact aetiology is not clear, what do you think the aetiology for ectopic tooth is in your case?

\section{Reply to No 3}

There is no exact etiology for ectopic teeth development, there are multiple theories to get closer to the exact cause. We will add the following statement to get closer to the etiology of developing ectopic molar in our case:

"In our case, we may suggest that the theory of the associated pathology with the third molar might have caused its ectopic location".

(To be added at the end of the first paragraph in discussion).

\section{Comment No 4}

Discussion: How many cases of ectopic teeth in the maxillary sinus were reported so far? And how many of them were for third molars? 


\section{Reply to No 4}

According to latest review of literature 2018 (added ref no 2) there were 51 patients were observed, with higher prevalence of ectopic teeth in the third molars, 21 cases.

Lombroni L, Farronato G, Santamaria G, Lombroni D, Gatti P, Capelli M. Ectopic teeth in the maxillary sinus: A case report and literature review. Indian J Dent Res. 2018;29(5):667.

Competing Interests: no competing interest

The benefits of publishing with F1000Research:

- Your article is published within days, with no editorial bias

- You can publish traditional articles, null/negative results, case reports, data notes and more

- The peer review process is transparent and collaborative

- Your article is indexed in PubMed after passing peer review

- Dedicated customer support at every stage

For pre-submission enquiries, contact research@f1000.com 